\title{
PRIORITIZATION OF FOREST FIRE HAZARD RISK SIMULATION USING HYBRID GREY RELATIVITY ANALYSIS (HGRA) AND FUZZY ANALYTICAL HIERARCHY PROCESS (FAHP) COUPLED WITH MULTICRITERIA DECISION ANALYSIS (MCDA) TECHNIQUES - A COMPARATIVE STUDY ANALYSIS
}

\author{
Bernard KUMI-BOATENG $\mathbb{B}^{*}$, Michael Stanley PEPRAH ${ }^{\mathbb{D}}$, Edwin Kojo LARBI ${ }^{\mathbb{C}}$ \\ Department of Geomatic Engineering, University of Mines and Technology, Tarkwa, Ghana
}

Received 22 May 2020; accepted 17 August 2021

\begin{abstract}
Forests are important dynamic systems which are widely attracted by wild fires worldwide. Due to the complexity and non-linearity of the causative forest fire problems, employing sophisticated hybrid evolutionary algorithms is a logical task to achieve a reliable approximation of this environmental threats. This estimate will provide the outline of priority areas for preventing activities and allocation of fire fighters' stations, seeking to minimize possible damages caused by fires. This study aims at prioritizing the forest fire risk of Wassa West district of Ghana. The study considered static causative factors such as Land use and land cover (which include forest, built-ups and settlement areas), slope, aspect, linear features (water bodies and roads) and dynamic causative factors such as wind speed, precipitation, and temperature were used. The methods employed include a Hybrid Grey Relativity Analysis (HGRA) and Fuzzy Analytical Hierarchy Process (FAHP) techniques. The fuzzy sets integrated with AHP in a decision-making algorithm using geographic information system (GIS) was used to model the fire risk in the study area. FAHP and HGRA methods were used for estimating the importance (weights) of the effective factors in forest fire modelling. Based on their modelling methods, the expert ideas were used to express the relative importance and priority of the major criteria and sub-criteria in forest fire risk in the study area. The expert ideas were analyzed based on FAHP and HGRA. The major criteria models and fire risk model were presented based on these FAHP and HGRA weights. On the other hand, the spatial data of the sub criteria were provided and assembled in GIS environment to obtain the sub-criteria maps. Each sub-criterion map was converted to raster format and it was reclassified based on risks of its classes to fire occurrence. The maps of each major criterion were obtained by weighted overlay of its sub criteria maps considering to major criterion model in GIS environment. Finally, the map of fire risk was obtained by weighted overlay of major criteria maps considering to fire risk model in GIS. The results showed that the FAHP model showed superiority than HGRA in prioritizing forest fire risk of the study area in terms of statistical analysis with a standard deviation of $0.09277 \mathrm{~m}$ as compared to $0.1122 \mathrm{~m}$ respectively. The obtained fire risk map can be used as a decision support system for predicting of the future trends in the study area. The optimized structures of the proposed models could serve as a good alternative to traditional forest predictive models, and this can be a promisingly testament used for future planning and decision making in the proposed areas.
\end{abstract}

Keywords: fire hazard risk modelling, fuzzy logics, grey relativity analysis, multicriteria decision analysis, soft computing techniques.

\section{Introduction}

Forest fires studies have become obligatory in the past and recent decades since it plays a critical role in landscape transformation, vegetation succession, soil degradation and air quality. Forest fires are one of the most hazardous natural occurring disasters which are the most vital sources of land degradation that lead to deforestation and desertification processes (Fernandes et al., 2019;
Eskandari, 2017). Improvements in fire risk modelling and predictions are very crucial to reduce the negative impacts of fire, either by lessen burn severity or intensity through fuel management, or by aiding the natural vegetation recovery using post fire treatments. Fire risk is an important concept that shapes significantly in fire management planning. It is an assessment of the probability of fire occurrence that determines the ease of ignition, probability of combustion, and fire prone areas (Gai et al., 2011). Forest

*Corresponding author. E-mail: kumi@umat.edu.gh 
fire risk models are considered in three parts thus, hazards identification, vulnerability analysis, and emergency response capacity analysis. With the global climate change and the impact of human activity, the forest areas reduce rapidly, while the forest fire results in most of the reduction. Because it is an uncontrolled fire that occurs in the countryside or a wilderness area, forest fire usually causes destruction of fauna and flora, erosion, soil degradation, tree weakness, habitats destruction, human health damages, landscape beauty reduction, loss of life, loss of property and causes harm to the ecology and environment of a region (Fernandes et al., 2019; Gai et al., 2011). In addition to causing the increase of gases in the atmosphere, such as carbon dioxide, carbon monoxide, methane gas and nitrous gases, that are responsible for increasing the greenhouse effect and causing global respiratory problems. The understanding of the nature of the causing factors of fire risk including its effects and ecosystem responses are a challenging to both researchers, governmental and nongovernmental agencies and fire fighters' managers (Peprah et al., 2018; Addai et al., 2016; Amissah et al., 2010). Also, the overriding role of anthropogenic factors in regulating the fire events along with vegetation, climatic and topographic factors makes the fire risk prediction highly stimulating external causes leading to fire ignition. Many natural and anthropogenic factors may cause the fire occurrence in the forest areas. The natural factors include topographic factors which include (elevation, slope, and aspect), biologic factors (vegetation type and density, leaf litter depth and moisture, and soil characteristics) and climate factors (temperature, relative humidity, precipitation, and wind velocity). The anthropogenic factors are related to human activities in the forest areas (agricultural activities, recreational activities and existence of forest roads and settlements) (Eskandari, 2017).

Wildland fire is one of the most ubiquitous of all terrestrial disturbance agents. Evidence from a variety of sources suggests that wildfire has been an important component of the natural environment for at least 350 million years (Perry, 1998). Ignitions caused through human actions, whether deliberate or accidental, have become the most common source of wildland fire (Suresh et al., 2016). As a result of human-altered fire regimes, many ecosystems have undergone significant amount of change as fireinduced communities have become more prevalent. The fire risk calculation consists in verifying the probability of the fire occurring in determined place, that is, the chance of ignition. So, it is possible to do a critical evaluation of fire occurrence, and do the correct monitoring and prevention of burned areas, using objective tools. Such events and their accurate prediction are of great importance to those seeking to understand and manage fire prone ecosystems (Perry, 1998). Models predicting the rate of fire spread may be classified as physical, semi-physical or empirical according to the nature of their construction. Spatial information technologies such as remote sensing and geographic information system (GIS) offer great potential for effective modelling of wildland fire behaviour.
Forest fire research has two principal objectives; first to establish fire danger and thereby develop fire danger rating systems, and secondly, to develop methods which enable the accurate quantification of wildland fire events. The spread of fire through any bad means involves a number of complex chemical and physical process, and these have been considered by a significant amount of research. The variables used in the fire risk calculation can be of two types; some derived from factors that do not change in a short period of time called static, and those who vary in shorter time period called dynamic. The first ones include the land use and land cover, slope, types of vegetation, types of soil, road and settlement proximity. Moreover, the dynamic variables include the meteorological data, such as temperature, wind intensity and direction, humidity, and many other more. There are a lot of approaches used in the fire risk modelling, statistical methods such as logistics regression (Goldarag et al., 2016), quantitative and qualitative methods based on expert knowledge, such as Multi-Criteria Decision Analysis (MCDA) (Yakubu et al., 2015, 2018a; Addai et al., 2016; Amissah et al., 2010). Besides artificial intelligence methodologies, for example Artificial Neural Networks (ANN) (Fernandes et al., 2019; Eskandari, 2017; Goldarag et al., 2016; Maeda et al., 2009; Alonso-Betanzos et al., 2003) and Fuzzy logics (Eskandari, 2017; Sharma et al., 2012; Chang \& Wang; 2009; Vahidniaa et al., 2008), have been used for forest fires risk modelling and yielded accurate results. Some researchers have investigated the relation between various factors and fire occurrence in the forests as detailed in the following literatures (Stolzenburg, 2001; Stolle et al., 2003; Lozano et al., 2008; Martinez et al., 2009; Zumbrunnen et al., 2011; Jurdao et al., 2012; Eskandari et al., 2013a; Chuvieco et al., 2014; Eskandari, 2015). Also, the diversity of factors that affect the beginning and spreading of a forest fire integrating the use of an integrated analysis approach is recorded in (Chuvieco \& Congalton, 1989). In recent times, Geographic information system (GIS) applications provide adequate tools to manipulate and manage the spatial information and are widely applied to model forest fire risk. Various researchers have applied GIS for forest fire risk modeling by different methods (Chuvieco \& Congalton, 1989; Teodoro \& Duarte, 2013; Eskandari \& Chuvieco, 2015). Moreover, many methods have been used for fire risk modeling in the world. Some studies were performed by Dong model (Dong et al., 2005; Erten et al., 2005; Eskandari et al., 2013b). Also, some researchers have applied the Analytic Hierarchy Process (AHP) to model the fire risk (Akay \& Erdogan, 2017; Gai et al., 2011; Suresh et al., 2016; Durmaz et al., 2008; Chuvieco \& Congalton, 1989; Vadrevu et al., 2010; Sowmya \& Somashekar, 2010; Atesoglu, 2014). In addition to that, some others have used the logistic regression to model the fire ignition probability (Rollins et al., 2004; Martinez et al., 2009; Jurdao et al., 2012; Sitanggang et al., 2013; Eskandari \& Chuvieco, 2015), while some others have used artificial neural network (ANN) to predict the fire regimes (Vasconcelo et al., 2001; Alonso-Betanzos et al., 2002; Vakalis 
et al., 2004, Vasilakos et al., 2009; Satir et al., 2016). Support Vector Machine (SVM) has also been proposed for fire risk modelling in some other studies (Cortez \& Morais, 2007; Sakr \& Elhajj, 2010).

However, until now, no study has employed FAHP and HGRA methods integrated with GIS for fire risk modelling in the forests of Ghana. In this study, FAHP and HGRA approach in a multi criteria decision making (MCDM) framework considering GIS has been applied for fire risk modelling through a risk map in a part of Wassa West District forests of Ghana. This modelling method uses the expert ideas to express the importance and priority of effective factors in forest fire modelling. These expert ideas are expressed by linguistic variables (just equal, equally important, weakly more important, strongly more important, very strongly more important, and absolutely more important) for comparing of the effective factors in fire occurrence (Chang, 1996). The fuzzy sets were integrated in the modeling process to express the uncertainty and to get the more accurate results than the AHP method. So, weights and maps of effective factors have fuzzy characteristics in this modeling approach. Finally, the fire risk model is obtained based on the fuzzy weights. The map obtained from FAHP and HGRA models in this study are capable to predict the future fires in the study area as a function of topographic, biologic, climatic, and anthropogenic factors. In the first step of this research, a hierarchical structure of fire risk criteria and sub-criteria is developed and the criteria and sub-criteria maps are prepared. In the second step, the weights of criteria and sub-criteria are determined and the fire risk model is obtained using FAHP and HGRA. In the last step, the fire risk map is obtained by weighted overlay of the criteria considering to fire risk model in GIS. Finally, the fire risk map is compared to see their predictive performance in assessing fires risk in the study area. Numerous models for assessing fire risk have been developed throughout the world. Numerous researchers have made used of the Saaty's AHP (Saaty, 1980), modified and fuzzified to formulate and control uncertainty. Hence trapezoidal membership function for comparison ratios in AHP has been formulated and a new approach for triangular case has been developed (Chang \& Wang, 2009; Sharma et al., 2012). Triangular fuzzy member is a spread class of fuzzy member whose membership is defined by the three real members (Vahidniaa et al., 2008). The mathematics of fuzzy set theory is described in fuzzy sets (Zadeh, 1965). The use of fuzzy AHP and GIS and its different methods and applications has been well defined (Vahidniaa et al., 2008). AHP is a useful technique in decision making that has been widely used as an efficient multicriteria decision analysis tool for a weight estimation technique in different cases (Peprah et al., 2018; Larbi et al., 2018).

The western region of Ghana presents a lot of fire spots in the summer times, when the weather is dry. The aim of this study is to prioritize future fire risk areas of Wassa West District located in the Western South of Ghana. The proposed modelling is to create an artificial intelligence technique with HGRA and FAHP training. A multicriteria decision analysis to do the prediction of most propitious fire areas is expected, where it can be introduced the input variables at any period that desire to be determined. This estimate will provide the outline of priority areas for prevention activities and allocation of firefighting resources, seeking to minimize possible damages caused by fires. Wildland fire managers require spatially explicit and comprehensive information on fire risk for long term planning (Durmaz et al., 2008; Sharma et al., 2012). This planning should focus on formulating protection and prevention strategies that are appropriate in high risk areas. However, fire risk mapping is an extremely difficult and complex process requiring expertise in fire behaviour, human activities, fuels modelling, topography, ecology and GIS. This paper evaluates and presents fire risk through spatial analysis and mapping. Spatial analysis of fire risks maps was also made to determine the efficiency of many factors that influence fire risk, slope, insolation, fuel and human activities. As a result, the fire risk map was developed to incorporate topographic, and meteorological map produced from available existing data obtained from the survey and mapping division department. Application of the fire risk mapping was tested. The resulting maps will provide coarse grained, broad scale information to spatially assess both the hazards and risks of wildland fire. This will enable fire managers to make sound decisions concerning all phases of fire management planning. The purpose of this study is to develop a forest fire risk assessment and mapping model to identify, classify and map fire hazard areas. Such map will help to minimize the frequency of forest fire, advert damage and plan forest fire protection construction. Also, the study is linked to management and policy making strategies, such as forest management, land use planning and suitable management of natural resources. Moreover, it aims to help prevent forest fire by taking precautions. It also aims to be helpful for authorities coping during the event of occurrence of fire.

\section{Study area}

The study area (Figure 1) is situated in the middle part of Western South Region of Ghana with geographical coordinates of latitude $5^{\circ} 30^{\prime} \mathrm{N}$ to $6^{\circ} 15^{\prime} \mathrm{N}$ and longitude $1^{\circ} 45^{\prime} \mathrm{W}$ to $2^{\circ} 11^{\prime} \mathrm{W}$. It has a total land area of about $2578 \mathrm{~km}^{2}$ with Aboso as its capital (Larbi et al., 2018). It is bounded to the west by Sefwi Wiaso and Aowin districts, to the south by Ellembele and Jomoro, to the southeast by PresteaHuni Valley and to the north by Bibiani. The area is well known for mining activities due to the availability of natural resources such as Gold, Manganese and Bauxite which contributes significantly to the economic development of Ghana (Boye et al., 2018; Joe-Asare et al., 2018). There is a good network of water bodies such as rivers and streams, notable among them are river Tano and Ankobra but most of these water bodies are polluted due to mining and farming activities. The main traditional practice of the inhabitants in the district is farming of economic crops such 


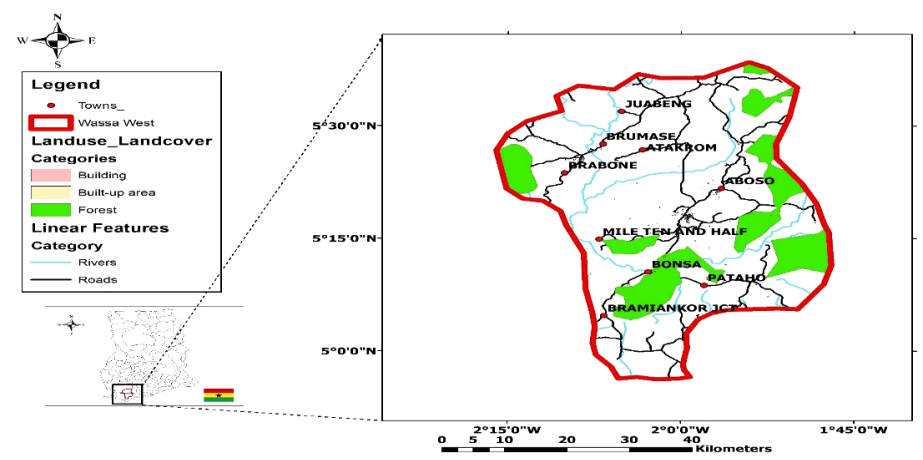

Figure 1. The study area

as cocoa, rubber, oil palm, citrus and kola (Avotri et al., 2002). It has a tropical climate associated with significant rainfalls and a short dry season (Peprah \& Mensah, 2017). There are two main rainfall regimes: thus; March to July and September to early December and the dry season starts from October to February. The interplay of heavy rainfall and soil types find expression in the vegetation cover. The semi deciduous forest is found in the northern part while the tropical rainforest is to the south where rainfall is heaviest (Larbi et al., 2018). Geographically, the lands are generally undulating with steep slopes parallel to each other and to the strike of the rocks in the North south direction with several hills making farming and other developmental activities a bit stressful (Kortatsi, 2004). It is found within the main gold belt of the Republic of Ghana that stretches from Axim in the Southwest direction, to Konongo in the Northeast direction (Kortatsi, 2004; Asklunel \& Eldvall, 2005). The type of coordinate system used in the study area is the Ghana projected grid derived from the Transverse Mercator $1^{\circ} \mathrm{NW}$ and the (WGS84) (UTM Zone 30N) (Yakubu et al., 2018b; Peprah et al., 2017). The average annual temperature is $26^{\circ} \mathrm{C}$ with small daily temperature variations. Relative humidity varies from $61 \%$ in January to a maximum of $80 \%$ in August and September (Peprah \& Mensah, 2017). It has an average annual precipitation of $1696 \mathrm{~mm}$. A detailed of the geology of the place can be found in (Asante-Annor et al., 2018).

\section{Resources and methods used}

\subsection{Resources}

The resources used for the investigating of the research findings include: Annual Climate data that spans from 2012 to 2018 obtained from World Climate website; Ghana Country Shape files (slope, Aspect, Elevation, land use-landcover and water bodies) obtained from the Survey and Mapping Division Department; ArcGIS software; Minitab and Microsoft office software.

\subsection{Methods used}

\subsubsection{Model generation}

The Forest Fire Model was generated in the ArcGIS environment as given in Eq. (1):

$$
F=\sum_{i=1}^{n} W_{i} C_{i} \prod_{j=1}^{n} r_{j}
$$

where $F$ - Forest fire Model; $W_{i}$ - weight of variables; $C_{i}$ - Model variables; $r_{j}$ - Restrictions.

\subsubsection{Hybrid Grey Relativity Analysis (HGRA)}

Grey Relational Analysis is a method developed by Sir Taguchi and was used in this study for the optimal selection and weighting of multi-criteria factors in forest fire risk modeling. The Taguchi method employs a statistical measure of performance known as signal to noise ratio $(\mathrm{S} / \mathrm{N})$ for its analysis. Orthogonal array experiments were developed by Genichi Taguchi to help in optimal settings of process control parameters through minimization of the variances in the experiments (Thapa \& Engelken, 2020). The quality characteristics for the "higher the better" was used for the normalization sequence of the land use-landcover and the windspeed criteria whereas the lower is better criteria was used for normalizing the slope, aspect, elevation, temperature, precipitation and the linear features. If the target value of the original sequence is infinite, the original sequence is normalized as given by Eq. (2) as:

$$
x_{i}^{*}(k)=\frac{x_{i}(k)-\min x_{i}(k)}{\max x_{i}(k)-\min x_{i}(k)},
$$

where $x_{i}{ }^{*}(k)$ is the normalized value of the $k^{\text {th }}$ performance characteristic in the $i^{t h}$ experiment; and $x_{i}{ }^{\star}(k)$ is the original $k^{\text {th }}$ performance value in the $i^{\text {th }}$ experiment. If the target value is "lower the better", the original sequence is normalized as according to Eq. (3) given as:

$$
x_{i}^{*}(k)=\frac{\max x_{i}(k)-x_{i}(k)}{\max x_{i}(k)-\min x_{i}(k)} .
$$

The deviation sequence is determined using Eq. (4) given as:

$$
\Delta_{0 i}=\left|x_{0}{ }^{*}(k)-x_{i}{ }^{*}(k)\right|,
$$

where $\Delta_{0 i}$ - Deviation sequence; $x_{0}{ }^{\star}(k)$ - Reference sequence or ideal series; and $x_{i}{ }^{*}(k)$ - Comparability sequence. The Grey Relational Coefficient is then calculated using Eq. (5) given as: 


$$
\xi_{i}(k)=\frac{\Delta_{\min }+\zeta \Delta_{\max }}{\Delta_{0 i}(k)+\zeta \Delta_{\max }},
$$

where $\xi_{i}(k)$ - Grey relational co-efficient, $\zeta$ - Distinguishing co-efficient, $\Delta_{\min }$ - the smallest value of $\Delta_{0 i}(k)$ whereas $\Delta_{\max }$ the largest value of $\Delta_{0 i}(k)$. The Grey Relational Grade is calculated by Eq. (6) given as:

$$
\gamma_{i}=\frac{1}{n} \sum_{k=1}^{n} w_{k}(k) \xi_{i}(k)
$$

where $\gamma_{i}$ - Grey Relational Grade (GRG), $w_{k}(k)-1, n-$ number of criteria used. The optimal rank of the GRG can be predicted using Eq. (7) given as:

$$
\varphi_{a}=\varphi_{m}+\sum_{i=1}^{r}\left(\overline{\varphi_{i}}-\varphi_{m}\right)
$$

where $\varphi_{m}$ the total mean of the GRG, $r$ - number of input parameters, $\overline{\varphi_{i}}$ - mean GRG value at the optimal value for the $i^{\text {th }}$ parameter. The GRG values are expressed as percentage weights for the various criteria rank. The ranking also helped in the pairwise comparisons of the Fuzzy AHP.

\subsubsection{Fuzzy AHP (FAHP)}

FAHP is one of the improved mathematical development using AHP techniques (Firoozi et al., 2017). In this case, triangular fuzzy numbers were used to classify the expert opinions. The fuzzy numbers are represented in the form $\tilde{q}_{i}=\left(a_{i j}, b_{i j}, c_{i j}\right)$ and in geometric space as shown in Figure 2. Fuzzy logic is a problem-solving control system that provides an easy way to arrive at definite solutions based on vague, noisy, ambiguous and imprecise information (Fazlollahtabar et al., 2009). Fuzzy logic approach mimics how a person would make a decision, only much faster. In multicriteria decision analysis (MCDA) method application, the decision tree is formed to prioritize the various criteria and sub-criteria. The judgement matrix is then formed based on the respondents and experts' advice. Consider the fuzzy judgement matrix given in Eq. (8) as:

$$
\left[\begin{array}{cccc}
(1,1,1) & \left(a_{12}, b_{12}, c_{12}\right) & \ldots & \left(a_{1 n}, b_{1 n}, c_{1 n}\right) \\
\left(a_{21}, b_{21}, c_{21}\right) & (1,1,1) & \ldots & \left(a_{2 n}, b_{2 n}, c_{2 n}\right) \\
\left(a_{n 1}, b_{n 1}, c_{n 1}\right) & \left(a_{n 2}, b_{n 2}, c_{n 2}\right) & \ldots & (1,1,1)
\end{array}\right] .
$$

The Geometric mean is calculated along each row using Eq. (9) given as:

$$
\tilde{\sigma}_{i}=\left(\prod_{j-1}^{n} \tilde{q}_{i j}\right)^{\frac{1}{n}}
$$

where $\tilde{\sigma}_{i}-$ Geometric mean values, $\tilde{q}_{i j}$ - Triangular Fuzzy Members, $n$ - number of criteria. The Fuzzy Geometric Mean is obtained by the column summation of the Geometric Mean of each criterion according to Eq. (10) given as:

$$
\sum_{i=1}^{n} \tilde{\sigma}_{i}=\tilde{\sigma}_{1}+\tilde{\sigma}_{2}+\tilde{\sigma}_{3}+\cdots+\tilde{\sigma}_{n}
$$

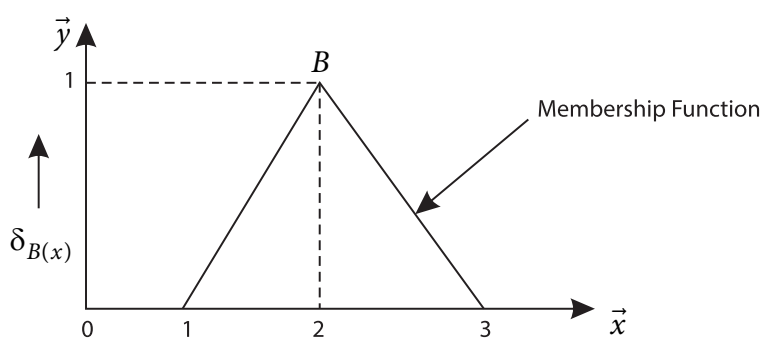

Figure 2. Triangular Fuzzy Membership

The Fuzzy weights are obtained by normalization according to Eq. (11) as:

$$
\tilde{r}_{i j}=\tilde{w}_{i j} \text {, }
$$

where $\tilde{r}_{i j}$ - normalized weights of the secondary variables (option $i$ weight than criterion $j$ ), $\tilde{w}_{i j}$ - weights of the main variable or criteria. The final weights, $\tilde{U}_{i}$ are thus obtained in Eq. (12) given as:

$$
\tilde{U}_{i}=\sum_{i=1}^{n} \tilde{w}_{i j} \tilde{r}_{i j} .
$$

\subsubsection{Consistency check}

To determine the consistency of the chosen criteria, a consistency check was carried out on the linguistic variables. The consistency ratio was used to check whether the threshold value proposed by Sir Saaty was not exceeded (Larbi et al., 2018). For consistency, the consistency ratio should not exceed $0.10\left(C_{r}\langle 0.10)\right.$. The consistency ratio is obtained by dividing the calculated consistency index by its corresponding criteria Random Index. First, the weighted sum is multiplied by the criteria matrix according to Eq. (13) given as:

$$
W_{s}=\left[\begin{array}{l}
w_{1} \\
w_{2} \\
w_{3} \\
w_{4}
\end{array}\right],
$$

where $W_{s}$ - weighted sum vector. The Eigen Vector is calculated by division of the weighted sum vector by the criteria weights given by Eq. (14):

$$
e_{i}=\frac{1}{\tilde{w}_{i j}}\left(w_{s}\right),
$$

where $e_{i}$ - Eigen vectors; $\tilde{w}_{i j}$ - weights of the main variable. The average eigen vectors is calculated by Eq. (15) given as:

$$
\lambda_{\max }=\frac{\sum_{i=1}^{n} e_{i}}{n},
$$

where $\lambda_{\max }$ - Average of the Eigen vectors; $n$ - number of criteria. The Consistency Index, $c_{i}$ is calculated by Eq. (16) as:

$$
C_{i}=\frac{\lambda_{\max }-n}{n-1} .
$$


The Consistency ratio is computed by Eq. (17) as:

$$
C_{r}=\frac{C_{i}}{R_{i}} .
$$

where $C_{r}$ - Consistency ratio, and $R_{i}$ - Random Index.

\subsubsection{Cost criteria}

The Cost friction surface is a raster dataset represented by grid cells. This is based on a set of defined criteria. Various thematic maps according to the defined cost criteria were generated in the ArcGIS environment to assist in identifying areas susceptible to fire risk hazards in intensifying degrees. In this study, eight (8) main cost factors were selected and used for the forest fire hazard risk analysis, five (5) static variables and three (3) dynamic variables according to the experts' advice were used. The factors were classified and weighted using both fuzzy AHP and HGRA (Hybrid Grey Relational Analysis) and the resulting maps were studied and compared. Table 1 is the classification of the forest fire hazard factors.

\section{Land Cover-Land Use}

Land Cover-Land Use forms the major static variable in forest fire risk modelling. Land cover represents the actual or physical presence of vegetation or other materials where vegetation is non-existent on the land surface (Fry et al., 2011). In this study, three main classes under land cover-land use were used. These include Forest reserves, Buildings and Built-up areas. Forest areas provide combustion grounds for wild fires. The forest fires are fueled by dry branches, stems and dry leaves. Human factors also play a major role in starting up forest fires. Built-up areas close to forest areas poses a higher risk of forest fire hazards due to human activities such as bush burning, hunting for wild animals, farming, accidentally leaving pieces of cigarettes in the bush. The rate of combustion is expedited by the dynamic factors (temperature, wind, humidity). The land cover- land use data was obtained from the Ghana country shapefiles. A map was then generated at a scale of 1:500 000 in the ArcGIS environment.

\section{Linear Features (Limiting Factors)}

The Linear features comprises of the roads and rivers in the study area. They are referred to as the limiting factors since it has a very low impact in the cause of the fire hazards. Roads help in emergency response whenever, there is outbreak of forest fire. It expedites the services of the forest fire brigade in firefighting. Water bodies has offered an extinguishing effect on forest fire hazards. Some water bodies flow through forest areas causing a reduction in the incidence of forest fires. Both data were also obtained from the Ghana country shapefiles and worked on in the ArcGIS environment.

\section{Slope}

Slope plays a major role in forest fire risks. Slope affects the airflow as well as the local micro-climate therefore affecting the fire spread. The contour topography from the country shape files was used in the generation of the Digital Elevation Model (DEM) of the study area. The DEM was then used to generate the slope data for the Fire risk analysis in ArcGIS environment.

\section{Elevation}

Elevation data is one of the main factors to be considered in forest fire risk modelling. An increase in altitude results in a decrease in temperature and a rise in humidity. As a result, there is a decrease in the occurrence of forest fire hazards. The Digital Elevation Model (DEM) of the study area was generated from the contour data as obtained from the Survey and Mapping Division Department.

\section{Aspect}

Aspect determines the amount of received radiation from the sun. The Aspect data was generated from the slope data using ArcGIS software. It was then classified into 4 cardinal directions namely North (N), South(S), East (E) and West (W) according to the intensity of the received radiation. The Aspect map had a resolution of $30 \mathrm{~m}$ by $30 \mathrm{~m}$.

\section{Wind speed ( $k p h$ )}

Wind speed is a very crucial meteorological variable in forest fire risk hazards. It determines the occurrence and the rate of spread of forest fires. The wind speed was measured in knots per hour (kph) using the Beaufort scale. The Annual wind speed was downloaded from the World Climate website, https://www.worldclim.org/data/index.html in a tiff file. It spans from 2012 to 2018 with $1 \mathrm{~km}$ by 1 $\mathrm{km}$ resolution. The wind speed was grouped into three (3) main classes. It formed the major criteria among the dynamic fire factors.

\section{Temperature}

Temperature is one of the main dynamic factors contributing to forest fire risk hazards. The higher the temperature, the faster the rate of combustion and vice versa. Temperature also reduces with increasing elevation and increases with a reduction in elevation. Forest Fire hazards are more likely to occur at places with hot temperatures (Tropical climate) compared to places of lower temperatures. The Annual Temperature data spans from 2012 to 2018. It was downloaded from the World Climate website, https:// www.worldclim.org/data/index.html in a raster format.

\section{Precipitation}

Precipitation is one of the main natural agents to consider in forest fire hazards. Forest fires as a result of lightening and spontaneous combustion emanates from natural factors such as rainfall (Gai et al., 2011). In this research, precipitation data (TRMM) over a period of 6 years (2012 to 2018) from the NASA website, (https://www.worldclim. org/data/index.html) was downloaded in raster format. The downloaded data had a resolution of $1 \mathrm{~km}^{2}$ which was 
later resampled to $150 \mathrm{~m}$ by $150 \mathrm{~m}$ resolution in the ArcGIS environment. The particular precipitation covering the entire study area was extracted and used for the study. The study area has an average precipitation of $1696 \mathrm{~mm}$.

Table 1. Classification of forest fire hazards

\begin{tabular}{|c|c|c|}
\hline \multicolumn{3}{|c|}{ Static Factors } \\
\hline Variables & Classes & Values \\
\hline \multirow{3}{*}{ Land use-Land cover } & Forest & 8 \\
\hline & Built-ups & 7 \\
\hline & Buildings & 6 \\
\hline \multirow{4}{*}{ Slope } & $0-0.12^{\circ}$ & 2 \\
\hline & $0.13-0.31^{\circ}$ & 3 \\
\hline & $0.32-0.87^{\circ}$ & 5 \\
\hline & $0.88-2.53^{\circ}$ & 7 \\
\hline \multirow{4}{*}{ Aspect } & North $(\mathrm{N})$ & 2 \\
\hline & East (E) & 4 \\
\hline & South (S) & 6 \\
\hline & West (W) & 8 \\
\hline \multirow{4}{*}{ Elevation } & $<60(\mathrm{~m})$ & 7 \\
\hline & $60-100(\mathrm{~m})$ & 5 \\
\hline & $100-140(\mathrm{~m})$ & 4 \\
\hline & $>140 \mathrm{~m}$ & 3 \\
\hline \multirow{2}{*}{$\begin{array}{l}\text { Linear Features } \\
\text { (Limiting factors) }\end{array}$} & Rivers & 1 \\
\hline & Roads & 2 \\
\hline
\end{tabular}

End of Table 1

\begin{tabular}{|l|l|c|}
\hline \multicolumn{3}{|c|}{ Static Factors } \\
\hline \multicolumn{1}{|c|}{ Variables } & \multicolumn{1}{|c|}{ Classes } & Values \\
\hline Dynamic Factors & $<1$ & 3 \\
\hline \multirow{3}{*}{$\begin{array}{l}\text { Wind speed }(\mathrm{kph}) \\
\text { (Beaufort scale) }\end{array}$} & 1 & 5 \\
\cline { 2 - 3 } & $(1-2)$ & 7 \\
\hline \multirow{5}{*}{ Precipitation } & $246-279(\mathrm{~mm})$ & 2 \\
\cline { 2 - 3 } & $279-304(\mathrm{~mm})$ & 3 \\
\cline { 2 - 3 } & $304-333(\mathrm{~mm})$ & 5 \\
\cline { 2 - 3 } & $333-370(\mathrm{~mm})$ & 2 \\
\hline \multirow{5}{*}{ Temperature } & $<24^{\circ} \mathrm{C}$ & 6 \\
\cline { 2 - 3 } & $25-26^{\circ} \mathrm{C}$ & 7 \\
\cline { 2 - 3 } & $>26^{\circ} \mathrm{C}$ & \\
\hline
\end{tabular}

\subsubsection{Weighted overlay of cost maps}

The cost criteria of the forest fire hazards were weighted using both the Grey Relativity Analysis and the Fuzzy AHP. The Different forest fire models of the study area were generated in the ArcGIS environment. Both the static and dynamic factors were overlaid using the weighted overlay function and later combined using the raster calculator for the final forest fire hazard model. Figure 3 is the flow chart of the weighted overlay of the various static factors. Figure 4 is the weighted overlay of the dynamic factors. The Combined Fuzzy and Grey Forest Fire Model is given in Figures 5 and Figure 6 respectively.

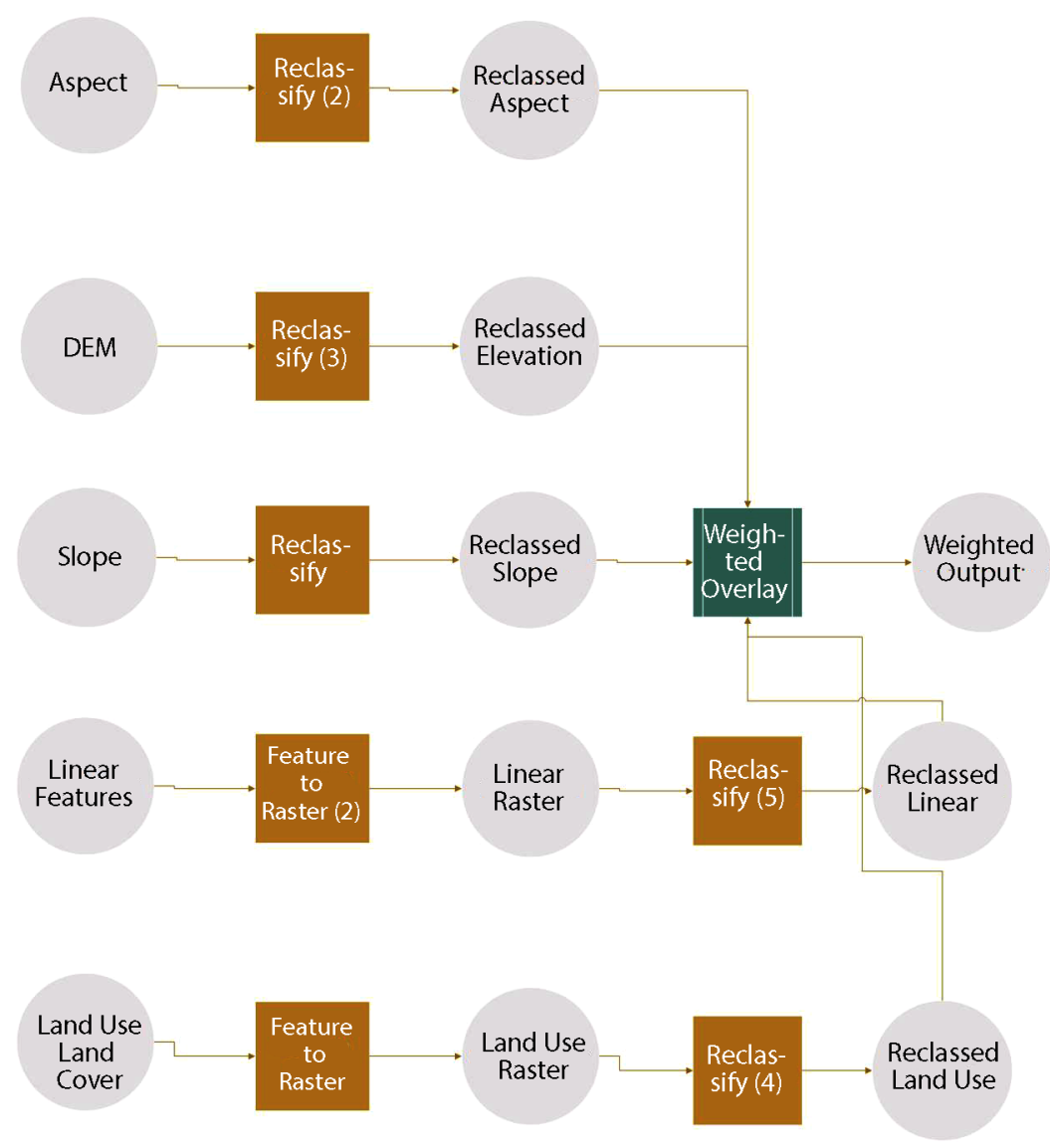

Figure 3. Flow chart of weighted static factors 


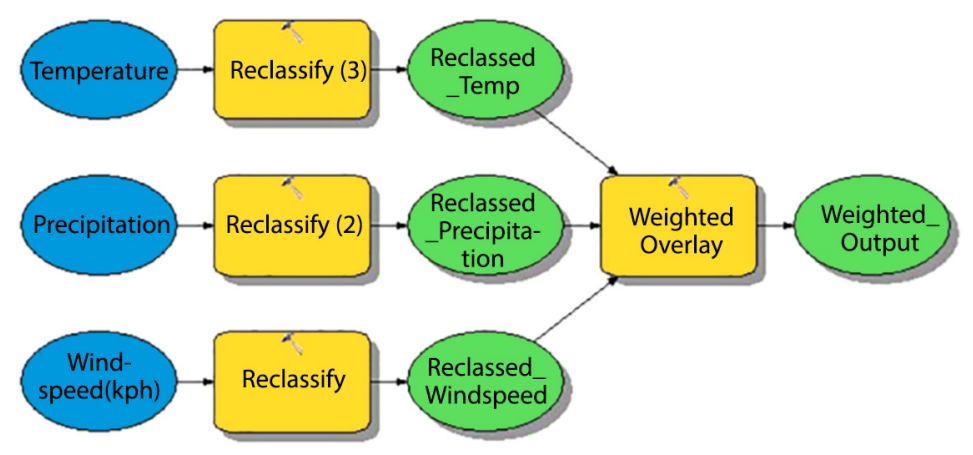

Figure 4. Flow chart of weighted dynamic factors

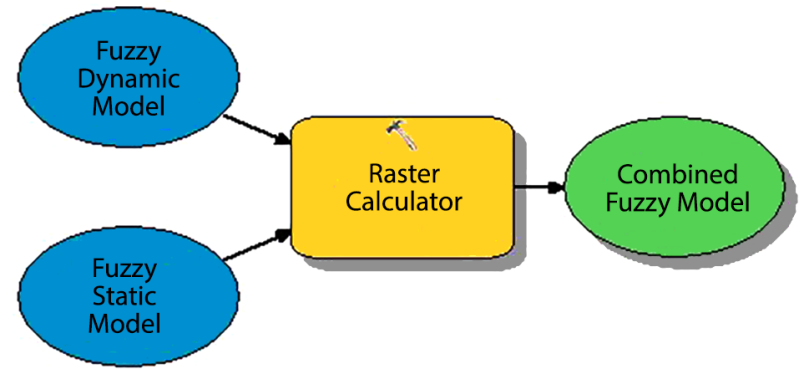

Figure 5. Combined fuzzy model

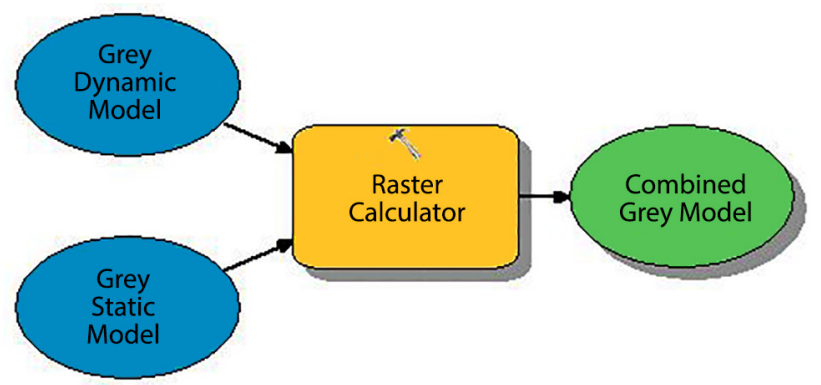

Figure 6. Combined grey model

\section{Results and discussion}

Both Fuzzy AHP and Hybrid Grey Relativity Analysis (HGRA) were used to assign weights to the various criteria. First, a consistency check was carried out to determine the consistency of the static and dynamic factors. The calculated Consistency ratio $\left(C_{r}\right)$ for the cost criteria was 0.10 . This implies the calculated weights were consistent. The consistent set criteria were then fed into the fuzzy AHP and HGRA model for the weight calculation. For the Fuzzy AHP, the triangular fuzzy member function was employed in the calculation. Eq. (17) shows the pairwise fuzzy matrix and the geometric means of the static cost factors. Eq. (18) shows the pairwise fuzzy matrix and the geometric means of the dynamic cost factors. The obtained Triangular fuzzy weights were defuzzied to obtain the crisp weights using the center of area method before it was finally normalized to obtain the percentage weights as shown in Table 2. Table 3 gives the grey relational coefficients, grades and the optimized weights according to the ranks.

$$
\left[\begin{array}{ccccccc}
n & L a & E & S & A & L i & G M \\
L a & (1,1,1) & (1,1,1) & (1,2,3) & (1,2,3) & (1,2,3) & (1,1.516,1.933) \\
E & (1,1,1) & (1,1,1) & (1,1,1) & (1,2,3) & (1,2,3) & (1,1.32,1.552) \\
S & \left(\frac{1}{3}, \frac{1}{2}, 1\right) & (1,1,1) & (1,1,1) & (1,1,1) & (1,2,3) & (0.803,1,1.246) \\
A & \left(\frac{1}{3}, \frac{1}{2}, 1\right) & \left(\frac{1}{3}, \frac{1}{2}, 1\right) & (1,1,1) & (1,1,1) & (1,1,1) & (0.644,0.758,1) \\
L i & \left(\frac{1}{3}, \frac{1}{2}, 1\right) & \left(\frac{1}{3}, \frac{1}{2}, 1\right) & \left(\frac{1}{3}, \frac{1}{2}, 1\right) & (1,1,1) & (1,1,1) & (0.517,0.66,1)
\end{array}\right],
$$

where $n$ - number of criteria; $L a$ - Land use-Landcover; $E$ - Elevation; $S$ - Slope; $A$ - Aspect; $L i$ - Linear features; and GM - Geometric Mean.

$\left[\begin{array}{ccccc}n & P & T & W & G M \\ P & (1,1,1) & (1,1,1) & \left(\frac{1}{3}, \frac{1}{2}, 1\right) & (0.693,0.794,1) \\ T & (1,1,1) & (1,1,1) & (1,1,1) & (1,1,1) \\ W & (1,2,3) & (1,1,1) & (1,1,1) & (1,1.26,1.442)\end{array}\right]$,

where $P$ - Precipitation, $T$ - Temperature; and $W$ - Wind speed.

Table 2. Normalized Fuzzy Weights

\begin{tabular}{|l|c|c|c|c|c|}
\hline Criteria(n) & $\begin{array}{c}\text { Lower } \\
\text { values }\end{array}$ & $\begin{array}{c}\text { Middle } \\
\text { Values }\end{array}$ & $\begin{array}{c}\text { Upper } \\
\text { Values }\end{array}$ & $\begin{array}{c}\text { Crisp } \\
\text { Weights }\end{array}$ & $\begin{array}{c}\text { Nor- } \\
\text { malized } \\
\text { Weights } \\
(\%)\end{array}$ \\
\hline $\begin{array}{l}\text { Land Use- } \\
\text { Land Cover }\end{array}$ & 0.149 & 0.289 & 0.488 & 0.309 & 28 \\
\hline Elevation & 0.149 & 0.251 & 0.392 & 0.264 & 24 \\
\hline Slope & 0.119 & 0.19 & 0.314 & 0.208 & 19 \\
\hline Aspect & 0.096 & 0.144 & 0.252 & 0.164 & 15 \\
\hline $\begin{array}{l}\text { Linear } \\
\text { Features }\end{array}$ & 0.077 & 0.126 & 0.252 & 0.152 & 14 \\
\hline Precipitation & 0.201 & 0.26 & 0.371 & 0.259 & 26 \\
\hline Temperature & 0.291 & 0.327 & 0.371 & 0.33 & 33 \\
\hline Wind Speed & 0.291 & 0.413 & 0.535 & 0.413 & 41 \\
\hline
\end{tabular}


Table 3. Normalized HGRA Weights

\begin{tabular}{|c|c|c|c|c|c|c|c|c|}
\hline \multirow{2}{*}{\begin{tabular}{|l|}
\multicolumn{1}{|c}{ Criteria(n) } \\
Land use- \\
Land Cover
\end{tabular}} & \multicolumn{5}{|c|}{ Grey Relational Coefficients } & \multirow{2}{*}{$\begin{array}{c}\text { GRG } \\
0.867\end{array}$} & \multirow{2}{*}{$\frac{\text { Weights (\%) }}{26}$} & \multirow{2}{*}{$\frac{\text { Rank }}{1}$} \\
\hline & 0.3333 & 1 & 1 & 1 & 1 & & & \\
\hline Elevation & 0.3333 & 1 & 0.4286 & 1 & 1 & 0.7521 & 22 & 3 \\
\hline slope & 1 & 1 & 0.4286 & 0.3333 & 1 & 0.7524 & 23 & 2 \\
\hline Aspect & 1 & 0.3333 & 0.4286 & 0.3333 & 0.3333 & 0.4857 & 15 & 4 \\
\hline Linear & 1 & 0.3333 & 0.3333 & 0.3333 & 0.3333 & 0.4667 & 14 & 5 \\
\hline \multirow{4}{*}{\multicolumn{2}{|c|}{ Dynamic factors }} & Criteria(n) & \multicolumn{3}{|c|}{ Grey Relational Coefficients } & GRG & Weights (\%) & Rank \\
\hline & & Temperature & 1 & 1 & 1 & 1 & 33 & 2 \\
\hline & & Precipitation & 1 & 0.3333 & 0.3333 & 0.556 & 19 & 3 \\
\hline & & Wind speed & 3 & 1 & 0.3333 & 1.444 & 48 & 1 \\
\hline
\end{tabular}

Note: GRG - Grey Relational Grade.

\subsection{Cost variable maps}

The various criteria maps were generated using the ArcGIS software. Figure 7 is the land Use-Land Cover map of the study area. Figure 8 represents the Aspect map of Wassa West District. Figure 9 shows the Elevation Model. The Linear features which comprises of roads and rivers as represented by Figure 10. Figure 11 shows the

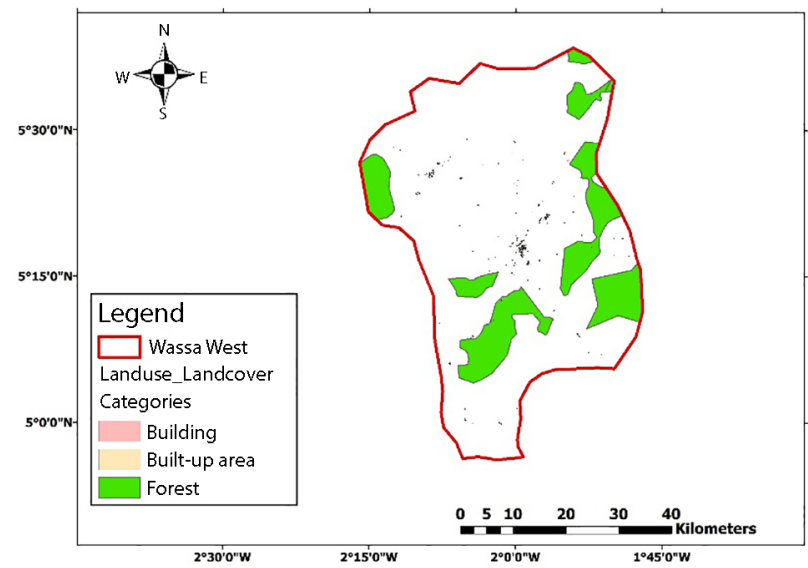

Figure 7. Land use-land cover map

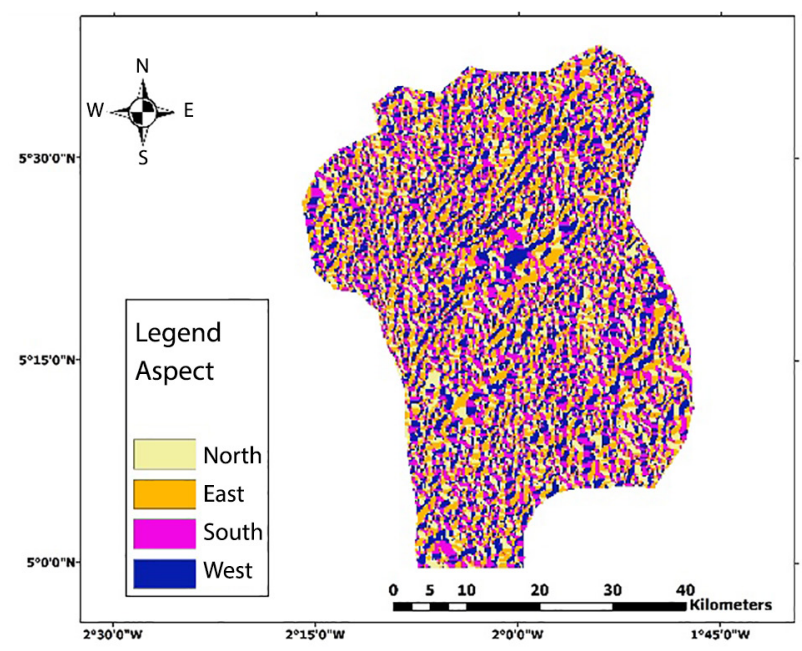

Figure 8. Aspect map of study area wind speed at the various areas in Wassa West District of Ghana. The Temperature and Precipitation maps are represented in Figure 12 and Figure 13 respectively. The slope map is shown by Figure 14. Figure 15 is the Final Forest Fire Model using Fuzzy AHP. Figure 16 is the Final Forest Fire Model using Hybrid Grey Relativity Analysis. Table 4 shows the respective areas and percentages of the fire hazard models.

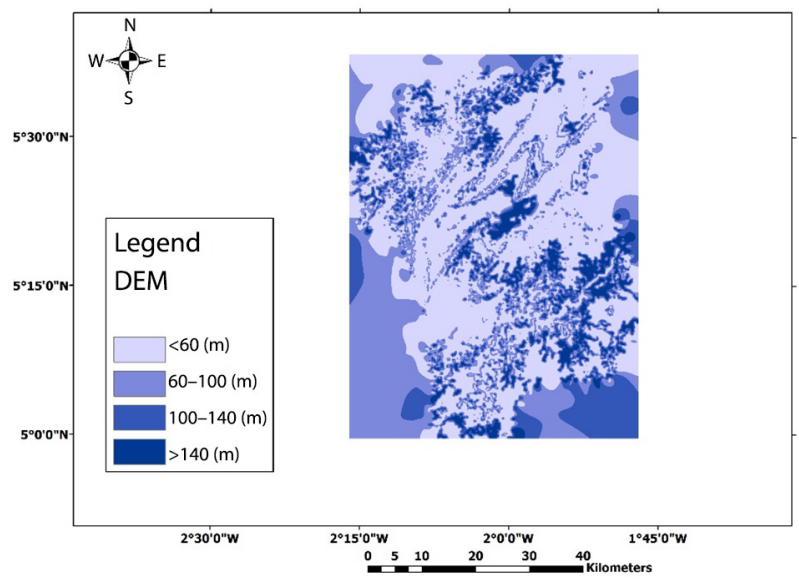

Figure 9. Elevation model

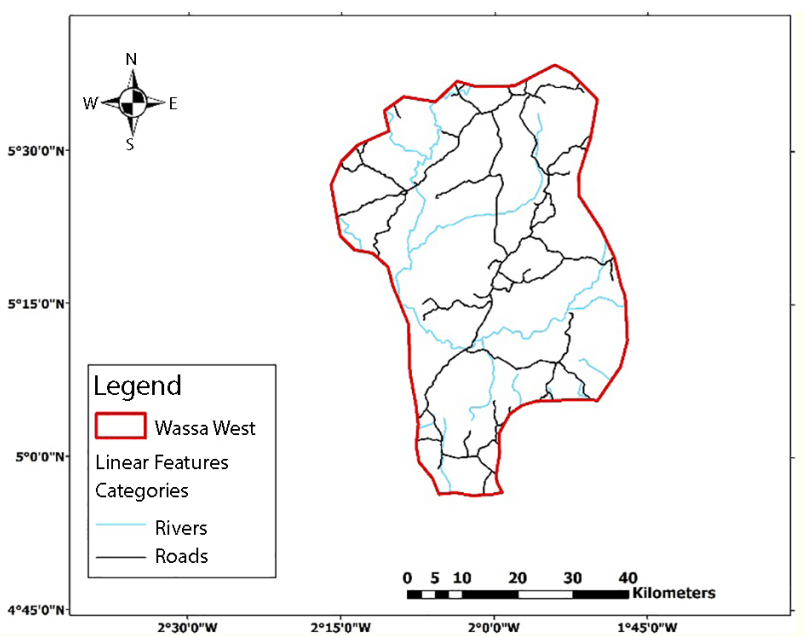

Figure 10. Linear features (roads and rivers) 


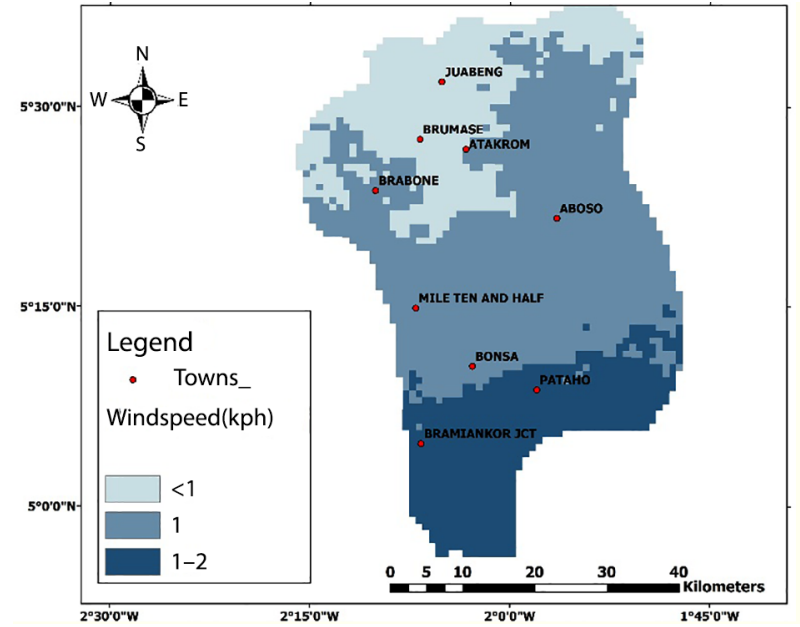

Figure 11. Wind speed map

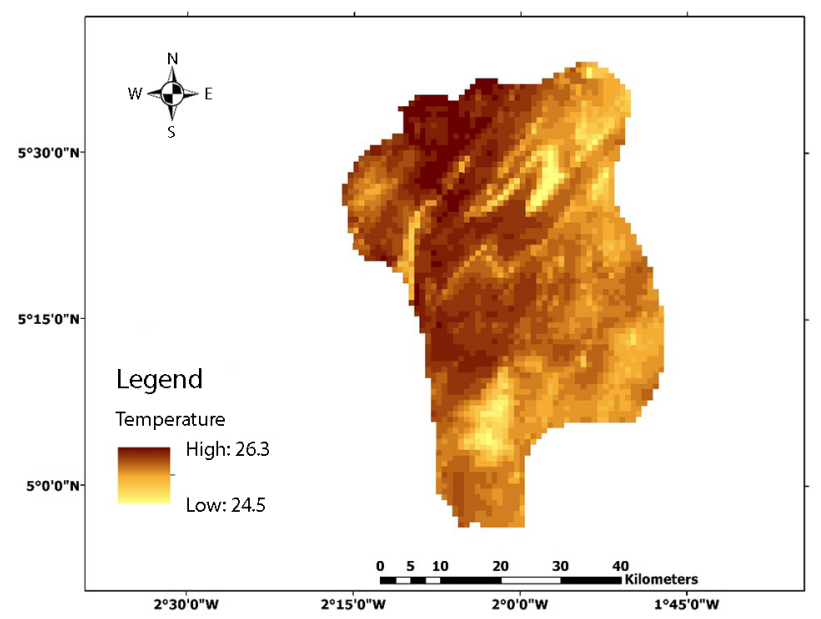

Figure 12. Temperature map

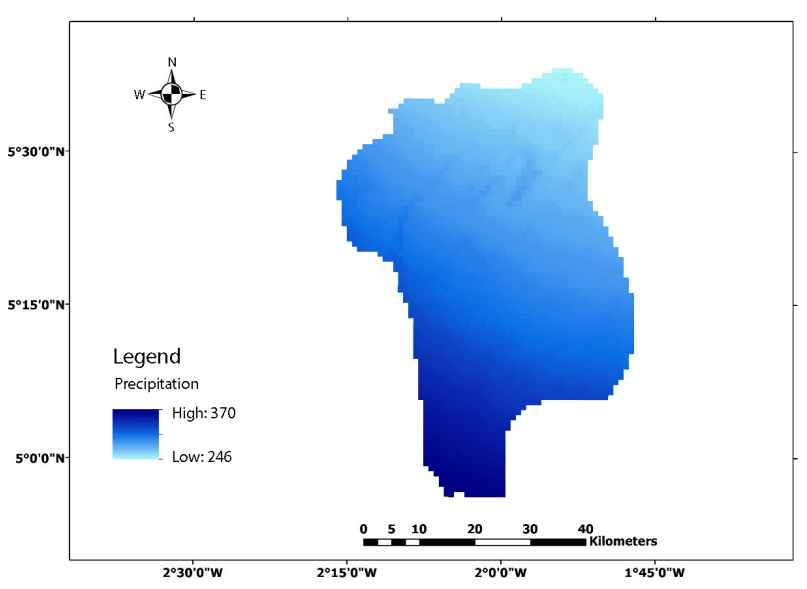

Figure 13. Precipitation map

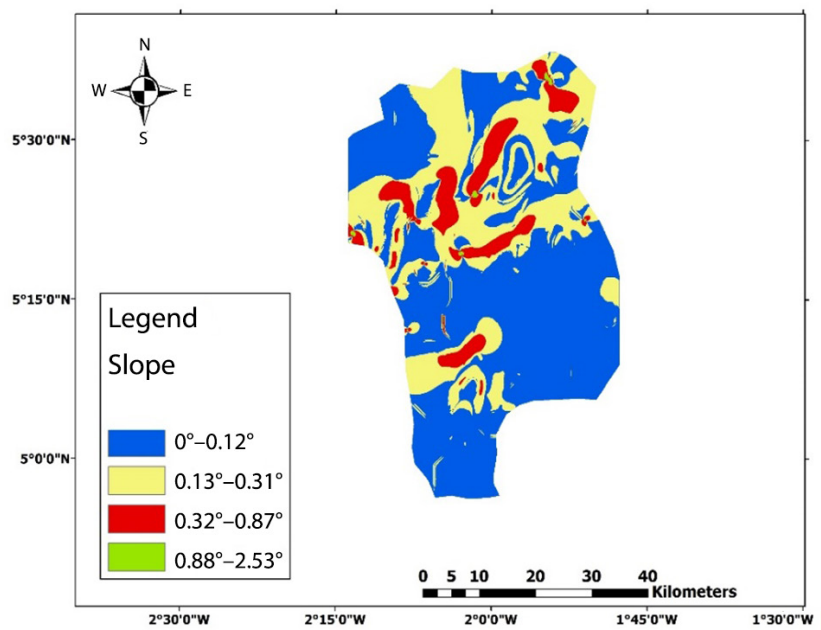

Figure 14. Slope map of study area

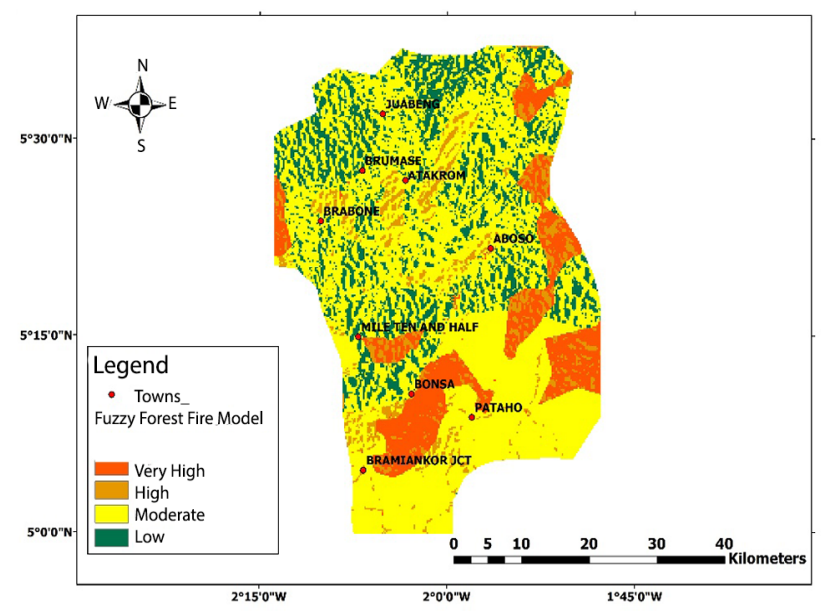

Figure 15. Fuzzy forest fire model

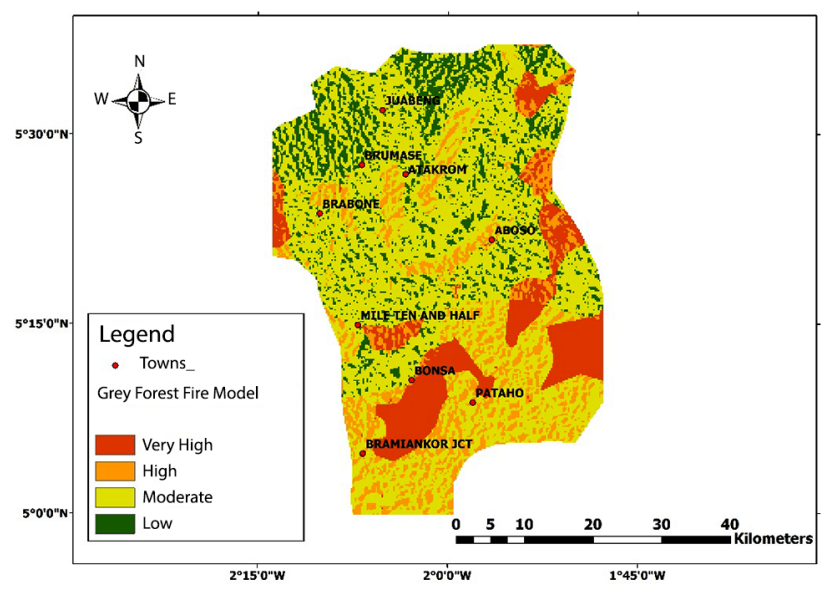

Figure 16. Hybrid grey forest fire model 
Table 4. Areas and percentage coverage of models

\begin{tabular}{|l|c|c|}
\hline \multicolumn{3}{|c|}{ Fuzzy AHP } \\
\hline \multicolumn{1}{|c|}{ Description } & Area $\left(\mathrm{km}^{2}\right)$ & Percentages (\%) \\
\hline Very High & 286.7412 & 11.8 \\
\hline High & 176.625 & 7.3 \\
\hline Moderate & 1521.42 & 62.7 \\
\hline Low & 442.32 & 18.2 \\
\hline \multicolumn{3}{|c|}{ HGRA } \\
\hline Very High & 308.6119 & 12.7 \\
\hline High & 336.29 & 13.9 \\
\hline Moderate & 1444.39 & 59.5 \\
\hline Low & 337.81 & 13.9 \\
\hline
\end{tabular}

\subsection{Discussion}

The study aims at developing a fire risk model for a forested area (Wassa West), a district in the Western Region of Ghana as well as comparatively analyzing the predictability strength of two mathematical models (fuzzy AHP and HGRA). The various cost factor maps; land use-land cover, slope, aspect, elevation, linear features, temperature, precipitation and wind speed were generated in the ArcGIS environment. The static factors were weighted separately from the dynamic factors using the weighted overlay function in the Spatial Analyst toolbox. Both factors were later combined using the raster calculator tool to generate the final forest fire risk model of the selected area. Four color codes were used for the final output maps; green for areas with lower risk of fire hazards, yellow for moderate vulnerability to fire hazards, orange represent areas with a high risk of fire hazards and red for areas with the highest risk of fire hazards. Two fire models were developed from the two mathematical models for comparative purposes. Generally, both methods proved very useful in fire risk modelling. Both methods went through the normalization process in their weight generation. Both methods accurately predicted the forest zones as areas with the highest fire risk hazards denoted by red color. The HGRA was found to accommodate and work with more criteria easily as compared to the AHP which encountered some problems in the course of increasing criteria number. The standard deviation values obtained from the weights of the fuzzy AHP was less than the HGRA. This implies, when both values are plotted, they will be more spread out in the HGRA whiles they will be clustered around the mean or expected value in the Fuzzy AHP. This means that the weights generated from the fuzzy AHP are more reliable compared to the HGRA. Upon careful observation of Figure 15 and Figure 16, it can be seen that, the hybrid Grey Relativity Analysis predicts more fire risk zones compared to the Fuzzy AHP. For instance, areas with high fire risks (orange color) in the Fuzzy AHP model are also relatively predicted by the HGRA but the HGRA predicts additional areas. This further confirms the results of the obtained standard deviations. In effect, the fire risk zones

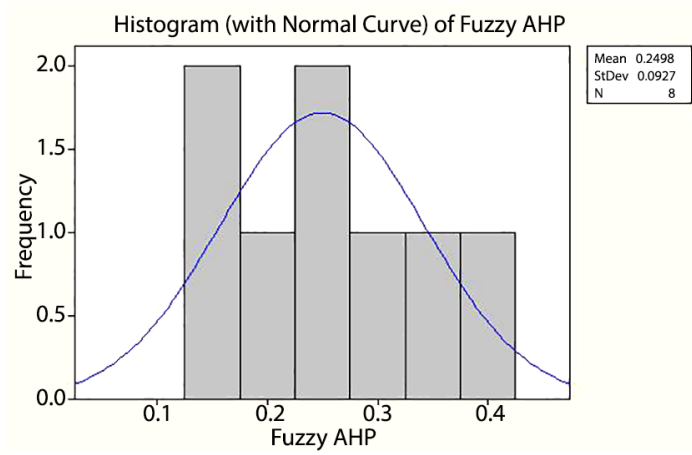

Figure 17. A normal histogram curve (fuzzy AHP)

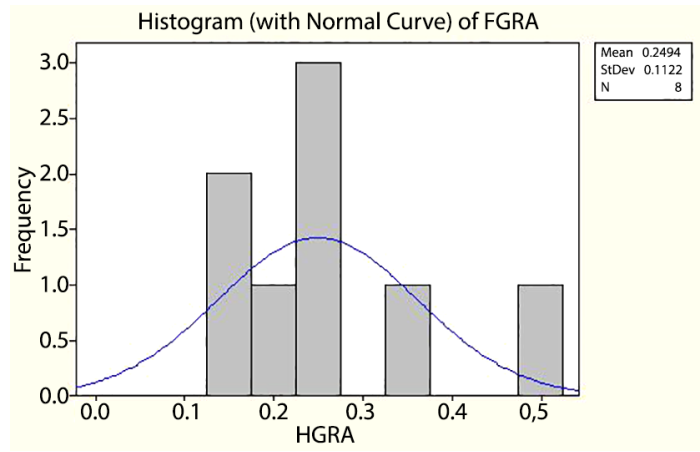

Figure 18. A normal histogram curve (HGRA)

appearing on both final maps are even prioritized by the fuzzy AHP model. This helps in filtering of the fire risk zones to make vivid, areas in higher need of firefighting resources and immediate attention. Table 4 shows the areas and percentage coverages of both mathematical models. Comparatively, The Fuzzy AHP predicted a less percentage of areas as Very high (11.8\%) and high (7.3\%) compared to the HGRA which predicted $12.7 \%$ as very high and $13.9 \%$ as high risk areas. Figure 17 shows a histogram graph with a normal distribution curve of the fuzzy AHP. The fuzzy AHP had a standard deviation of $0.0927 \mathrm{~m}$. Figure 18 is a histogram graph with a normal distribution curve of the HGRA. The standard deviation of the HGRA was $0.1122 \mathrm{~m}$. From both graphs, it can be seen that values are much closer to the mean or expected value in the fuzzy AHP as compared to the HGRA which are widely spread. Hence, upon deduction the fuzzy AHP proved to be a more reliable method compared to the HGRA. Fuzzy AHP is able to deal with the unbalanced scale of judgment introduced by human subjective preference due to the fuzzy logics, it is more able to reflect the human thinking style using different perspective approach (Askin \& Guzin, 2007).

\section{Conclusions and recommendations}

Susceptibility mapping and analysis of natural hazards, like landslide, flood, forest risk, tsunamis, earth quakes and earth tremors, volcanoes, sea floor mapping etc., is well known and is one of the fundamental prerequisites 
for future planning and risk management in any region. In this research, the MCDA, fuzzy AHP, HGRA and GIS methods were developed for forest risk hazard mapping assessment in Wassa West District of Ghana. The statistical and spatial analysis to obtain the forest fire risk map with these methods approach is more sophisticated than any other modelling approaches. The complexity of the required calculations and spatial analysis on the digital maps complicates the use of this approach. However, this approach showed acceptable accuracy for fire risk modelling. This paper presents a spatially weighted Index Model of forest fire risk hazards using Hybrid Grey Relativity Analysis (HGRA) and Fuzzy AHP. In the course of study, the various cost variables (static and dynamic) were mapped. The criteria were then weighted with the fuzzy AHP and HGRA to produce the output fire models using Weighted Overlay tool in the Spatial Analyst toolbox. The Raster Calculator tool was then used to combine the static and dynamic cost criteria to generate the final Fire Risk Hazard Models. Both Weighting Models proved very useful, but upon comparative analysis, the Fuzzy AHP proved more reliable compared to the HGRA as it was able to prioritize the fire risk zones. The performance of fuzzy AHP was evaluated and compared with the HGRA model. The results show that the fuzzy AHP is highly suitable for forest fire risk mapping at the moment. This is practically the case for urban areas with limited fire cases. Since the complexity of the models has an undeniable effect on their performance, a sensitivity analysis was carried out to find the most appropriate model. Results of this study showed that some portion of the study area had very high and high risk for fire occurrence. It can be demonstrated that some portion of the forest are exposed to the future fires. Regarding to the high accuracy of fuzzy AHP approach for fire risk modelling in this study, prediction of the future fires in the Wassa West forest is possible using the fire risk map obtained from this study. So, the preventing measures of the future fires' occurrences, thus; establishing of firefighting stations, scout teams, allocation of the required facilities for firefighting, etc. should be performed in the high-risk areas. It is noted that, the fuzzy AHP model in this study may be applied in whole forests of Ghana. The proposal model should be modified regarding to all the effective factors in forest fire occurrence in each area, so that the accordance of the obtained fire risk map with the actual fires will be increased. Lack of the fire database in Wassa West forests of Ghana was one of the limitations of this work. We propose that more accuracy assessment of this model using other real-time fire data is needed to evaluate the efficiency of fire risk map. The Standard deviation obtained for the Fuzzy AHP also implies its weights are relatively closer to the mean or expected value than the HGRA. Hence, The Fuzzy AHP is a much-preferred costing model to be used in fire risk modelling and other models. Fire Risk Models are very important as it will help in siting firefighting resource and enhance forestry safety (Gai et al., 2011). Fire Risk Models also helps to safeguard against future loss of lives and property. The fire models present a graphical plan to all firefighting stakeholders including the National Fire Service, Fire Brigade and other Emergency Response Units to enable them fight against fire outbreak in the best way possible through immediate response systems through prioritization of fire hazard risk zones. It is recommended that further research should be embarked upon to increase the number of criteria used. The studies can also be applied in other areas to control the risk of fire hazards. Government and other firefighting stakeholder institutions are encouraged to use this model to boost their emergency response by way of siting firefighting resources. The National Fire Service should dispatch trained personnel to high fire risk sites to educate and train the inhabitants on, firefighting methods as well as measures to be put in place to avoid fire outbreaks.

Using soft computing to predict fire risk is a good methodology that results in good response, but it is necessary to be cautious with the chosen of the causative criteria. In this study, the fuzzy AHP could predict very well with the fire prone areas, but didn't recognize with great accuracy points with low risks thus; the direction of the flow of the fires. Nevertheless, with good repeatability, testing other optimization methods, as well as executing the sensitivity analysis of the fire conditioning factors, are good subjects for future studies, which probably will result in achieving more reliable results. In future studies could be added more static variables, such as NDVI images and distances to roads and settlement areas. Also, it would be very interesting study for a longer period, to see seasonal changes in meteorological variables. Location of fire stations along the prone areas is highly recommend and education of farmers and inhabitants of such area about good farming practices and proper fire activities in avoidances of fire outbreaks.

The outcome of the present study can be used in taking mitigation measures to minimize the loss in agricultural production, lives and properties, game and wild animals' reserves, and economic cost to the nation. The results also provide information which will be instrumented for governmental agencies to optimally allocate firefighting stations. It is recommended that; the Town and Country Planning department should use this map for future redevelopment of the study area. Moreover, the Geological and Survey Department, Survey and Mapping Division Department, and Meteorological Department of the country should produce an up to date rainfall map, aspect map, forest hazard maps, and geomorphological map of the study area for further studies to review the affected areas and help give relevant solutions to mitigate the menace to prevent loss of lives and properties. However, other machine learning algorithms such as artificial neural network, decision tree, radial basis function, generalized regression neural network. convolution neural network, group method of handling data, game theory, least square support vector machines, random forest algorithms, genetic algorithms, monte Carlo simulation, multivariate adaptive regression splines, box Jenkins, extreme learning machines, gaussian approach, wavelet transform model, 
ARIMA, Bayesian network model, particle swarm optimization and many others that was not considered in this study can be used in the future research.

\section{Acknowledgements}

The authors would like to appreciate the anonymous reviewers for their helpful comments, time and effort that made this piece of knowledge a better paper. Our sincere appreciation also goes to the Survey and Mapping Division Department of Ghana for providing us with the necessary data used to carry out this work.

\section{References}

Addai, E. K., Tulashi, S. K., Annan, J. S., \& Yeboah, I. (2016). Trend of fire outbreaks in Ghana and ways to prevent these incidents. Safety and Health at Work, 7(4), 284-292. https://doi.org/10.1016/j.shaw.2016.02.004

Akay, A. E., \& Erdogan, A. (2017). GIS-Based multicriteria decision analysis for forest fire risk mapping. In ISPRS Annals of the Photogrammetry, Remote Sensing and Spatial Information Sciences, Vol. IV-4/WA, $20174^{\text {th }}$ International GeoAdvances Workshop (pp. 25-30), 14-15 October 2014, Safranboln, Karabuk, Turkey.

https://doi.org/10.5194/isprs-annals-IV-4-W4-25-2017

Alonso-Betanzos, A., Fontenla-Romero, O., GuijarroBerdiñas, B., Hernández-Pereira, E., Canda, E., Jimenez, J., Luis Legido, J., Muñiz, S., Paz-Andrade, C., \& Paz-Andrade, M. I. (2002). A neural network approach for forest fire risk estimation. In F. van Harmelen (Ed.), Proceedings of the $15^{\text {th }}$ European Conference on Artificial Intelligence (pp. 643-647). ECAI Publisher, France.

Alonso-Betanzos, A., Fontenla-Romero, O., GuijarroBerdiñas, B., Hernández-Pereira, E., Paz Andrade, M. I., Jiménez, E., Soto, J. L. L., \& Carballas, T. (2003). An intelligent system for forest fire risk prediction and fire fighting management in Galicia. Expert Systems with Applications, 25(4), 545-554. https://doi.org/10.1016/S0957-4174(03)00095-2

Amissah, I., Kyereh, B., \& Agyemang, V. K. (2010). Wildfire incidence and management in the forest transition zone of Ghana: Farmers' perspectives. Ghana Journal of Forestry, 26, 61-73. https://doi.org/10.4314/gjf.v26i1.66202

Asante-Annor, A., Konadu, S. A., \& Ansah, E. (2018). Determination of potential landfill site in Tarkwa area using multicriteria GIS, geophysical and geotechnical evaluation. Journal of Geoscience and Environment Protection, 6(10), 1-27. https://doi.org/10.4236/gep.2018.610001

Askin, O., \& Guzin, O. (2007). Comparison of AHP and fuzzy AHP for the multi-criteria decision-making process with linguistic evaluations (Unpublished Technical Report). İstanbul Ticaret Üniversitesi Fen Bilimleri Dergisi, 6, 65-85. https://dergipark.org.tr/en/download/article-file/199503

Asklund, R., \& Eldvall, B. (2005). Contamination of water resources in Tarkwa mining area of Ghana [Unpublished MSc Thesis]. Department of Engineering Geology, Lund University. https://xdocs.net/documents/contamination-of-waterresources-in-tarkwa-mining-area-of-ghana-5ded56a614621

Atesoglu, A. (2014). Forest fire hazard identifying. Mapping using satellite imagery-geographic information system and analytic hierarchy process: Bartin-Turkey. Journal of Environmental Protection and Ecology, 15(2), 715-725. https://www. academia.edu/18013307/FOREST_FIRE_HAZARD_IDEN-
TIFYING_MAPPING_USING_SATELLITE_IMAGERY_ GEOGRAPHIC_INFORMATION_SYSTEM_AND_ANALYTIC_HIERARCHY_PROCESS_BARTIN_TURKEY

Avotri, T. S. M., Amegbey, N. A., Sandow, M. A., \& Forson, S. A. K. (2002). The health impact of cyanide spillage at Goldfields Ghana limited (Unpublished Technical Report). Tarkwa, Ghana.

Boye, C. B., Peprah, M. S., \& Kodie, N. K. (2018). Geographic assessment of telecommunication signals in a mining community: A case study of Tarkwa and its environs. Ghana Journal of Technology, 2(2), 41-49. https://www.researchgate. net/publication/324089809_Geographic_Assessment_of_Telecommunication_Signals_in_a_Mining_Community_A_ Case_Study_of_Tarkwa_and_its_Environs

Chang, D. Y. (1996). Applications of the extent analysis method on fuzzy AHP. European Journal of Operational Research, 95(3), 649-655. https://doi.org/10.1016/0377-2217(95)00300-2

Chang, T. H., \& Wang, T.C. (2009). Using the fuzzy multi-criteria decision-making approach for measuring the possibility of successful knowledge management. Information Sciences, 179(4), 355-370. https://doi.org/10.1016/j.ins.2008.10.012

Chuvieco, E., Aguado, I., Jurdao, S., Pettinari, M. L., Yebra, M., Salas, J., Hantson, S., De la Riva, J., Ibarra, P., Rodrigues, M., Echeverria, M., Azqueta, D., Roman, M. V., Bastarrika, A., Martinez, S., Recondo, C., Zapico, E., \& Martinez-Vega, F. J. (2014). Integrating geospatial information into fire risk assessment. International Journal of Wildland Fire, 23(5), 606619. https://doi.org/10.1071/WF12052

Chuvieco, E., \& Congalton, R. G. (1989). Application of remote sensing and geographic information systems to forest fire hazard mapping. Remote Sensing of Environment, 29(2), 147159. https://doi.org/10.1016/0034-4257(89)90023-0

Cortez, P. G., \& Morais, A. (2007). A data mining approach to predict forest fires using meteorological data. In Proceedings of the $13^{\text {th }}$ Portuguese Conference on Artificial Intelligence (pp. 512-523). Portugal. http://piano.dsi.uminho.pt/ pcortez/fires.pdf

Dong, X. U., Li-min, D., Guo-fan, S., Lei, T., \& Hui, W. (2005). Forest fire risk zone mapping from satellite images and GIS for Baihe Forestry Bureau, Jilin, China. Journal of Forestry Research, 16(3), 169-174. https://doi.org/10.1007/BF02856809

Durmaz, B. D., Bilgili, E., Salam, B., Kucuk, O., Baysal, I., Kadiogullari, A. I., \& Baskent, E. Z. (2008, July 2-5). Spatial forest fire risk analysis and mapping using GIS. In $5^{\text {th }}$ International Conference on Geographic Information Systems (ICGIS 2008) (pp. 115-120). Faith University, Istanbul, Turkey. https:// www.academia.edu/22246612/Proceedings_of_the_5th_International_Conference_on_Geographic_Information_Systems_-_2008_Vol._2

Erten, E., Kurgun, V., \& Musaolu, N. (2005). Forest fire risk zone mapping from satellite imagery and GIS, a case study (Unpublished Paper). https://www.isprs.org/proceedings/XXXV/ congress/yf/papers/927.pdf

Eskandari, S. (2015). Investigation on relationship between climate change and fire in the forests of Golestan forests. Iranian Journal of Forest and Range Protection Research, 13(1), 1-10. https://www.cabdirect.org/cabdirect/abstract/20173172299

Eskandari, S. (2017). A new approach for forest fire risk modelling using fuzzy AHP and GIS in Hyrcanian forests of Iran. Arabian Journal of Geosciences, 10, 190. https://doi.org/10.1007/s12517-017-2976-2

Eskandari, S., \& Chuvieco, E. (2015). Fire danger assessment in Iran based on geospatial information. International Journal 
of Applied Earth Observation and Geoinformation, 42, 57-64. https://doi.org/10.1016/j.jag.2015.05.006

Eskandari, S., Oladi, J., Jalilvand, H., \& Saradjian, M. R. (2013a). Role of human factors on fire occurrence in District Three of Neka Zalemroud forests-Iran. World Applied Sciences Journal, 27(9), 1146-1150.

Eskandari, S., Oladi, J., Jalilvand, H., \& Saradjian, M. R. (2013b). Detection of fire high-risk areas in Northern forests of Iran using Dong model. World Applied Sciences Journal, 27(6), 770-773. https://doi.org/10.5829/idosi.wasj.2013.27.06.503

Fazlollahtabar, H., Eslami, H., \& Salmani, H. (2010). Designing a fuzzy expert system to evaluate alternatives in fuzzy analytic hierarchy process. Journal of Software Engineering and Applications, 3(4), 409-418.

https://doi.org/10.4236/jsea.2010.34046

Fernandes, L. C., Cintra, R. S. C., Nero, M. A., \& da Costa Temba, P. (2019). Fire risk modelling using artificial neural networks. In H. Rodrigues et al. (Eds.), EngOpt 2018 Proceedings of the $6^{\text {th }}$ International Conference on Engineering Optimization (pp. 938-948). Springer.

https://doi.org/10.1007/978-3-319-97773-7_81

Firoozi, M. A., Goodarzi, M., \& Shirali, R. (2017). Assessment and potential survey of lands in Khuzestan Province using the Buckley geometric mean model and Geographic Information System (GIS). Open Journal of Geology, 7(3), 234-241. https://doi.org/10.4236/ojg.2017.73016

Fry, J., Xian, G., Jin, S., Dewitz, J., Homer, C., Yang, L., Barnes, C., Herold, N., \& Wickham, J. (2011). Completion of the 2006 national land cover database for the conterminous United States. Photogrammetric Engineering and Remote Sensing, 77(9), 858-864. https://www.researchgate.net/publication/279868428_Completion_of_the_2006_National_Land_ Cover_Database_for_the_Conterminous_United_States

Gai, C., Weng, W., \& Yuan, H. (2011). GIS-based forest fire risk assessment and mapping. In 2011 Fourth International Joint Conference on Computational Sciences and Optimization (pp. 1240-1244). IEEE. https://doi.org/10.1109/CSO.2011.140

Goldarag, Y. J., Mohammadzadeh, A., \& Ardakani, A. S. (2016). Fire risk assessment using neural network and logistic regression. Journal of the Indian Society of Remote Sensing, 44, 885-894. https://doi.org/10.1007/s12524-016-0557-6

Joe-Asare, T., Peprah, M. S., \& Opoku, M. M. (2018). Assessment of the potability of underground water from a small scale underground mine: A case study. Ghana Mining Journal, 18(2), 61-67.

https://www.ajol.info/index.php/gm/article/view/181344

Jurdao, S., Chuvieco, E., \& Arevalillo, J. M. (2012). Modelling fire ignition probability from satellite estimates of live fuel moisture content. Fire Ecology, 8(1), 77-97. https://doi.org/10.4996/fireecology.0801077

Kortatsi, B. K. (2004). Hydrochemistry of groundwater in the mining area of Tarkwa-Prestea, Ghana [Unpublished $\mathrm{PhD}$ Thesis]. University of Ghana, Legon-Accra, Ghana.

Larbi, E. K., Boye, C. B., \& Peprah, M. S. (2018). A GIS approach in optimal route selection in the mining communities using the Analytical Hierarchy Process and the Least Cost Path analysis - A case study. In $5^{\text {th }}$ UMaT Biennial International Mining and Mineral Conference (pp. 50-62). https://www. researchgate.net/publication/330780137_A_GIS_Approach_ in_Optimal_Route_Selection_in_the_Mining_Communities_Using_the_Analytical_Hierarchy_Process_and_the Least_Cost_Path_Analysis

Lozano, F. J., Suárez-Seoane, S., Kelly, M., \& Luis, E. (2008). A multi-scale approach for modeling fire occurrence probability using satellite data and classification trees: A case study in a mountainous Mediterranean region. Remote Sensing of Environment, 112(3), 708-719.

https://doi.org/10.1016/j.rse.2007.06.006

Maeda, E. E., Formaggio, A. R., Shimabukuro, Y. E., Arcoverde, G. F. B., \& Hansen, M. C. (2009). Predicting forest fire in the Brazilian Amazon using MODIS imagery and artificial neural networks. International Journal of Applied Earth $\mathrm{Ob}$ servation and Geoinformation, 11(4), 265-272.

https://doi.org/10.1016/j.jag.2009.03.003

Martinez, J., Vega-Garcia, C., \& Chuvieco, E. (2009). Humancaused wildfire risk rating for prevention planning in Spain. Journal of Environmental Management, 90(2), 1241-1252. https://doi.org/10.1016/j.jenvman.2008.07.005

Perry, G. L. W. (1998). Current approaches to modelling the spread of wildland fire: A review. Progress in Physical Geography, 22(2), 222-245. https://doi.org/10.1177/030913339802200204

Peprah, M. S., Boye, C. B., Larbi, E. K., \& Opoku Appau, P. (2018). Suitability analysis for sitting oil and gas filling stations using multi-criteria decision analysis and GIS approach - A case study in Tarkwa and its environs. Journal of Geomatics, 12(2), 158-166.

Peprah, M. S., Ziggah, Y. Y., \& Yakubu, I. (2017). Performance evaluation of the Earth Gravitational Model (EGM2008) - A case study. South African Journal of Geomatics, 6(1), 47-72. https://doi.org/10.4314/sajg.v6i1.4

Peprah, M. S., \& Mensah, I. O. (2017). Performance evaluation of the Ordinary Least Square (OLS) and Total Least Square (TLS) in adjusting field data: An empirical study on a DGPS data. South African Journal of Geomatics, 6(1), 73-89. https://doi.org/10.4314/sajg.v6i1.5

Rollins, M. G., Keane, R. E., \& Parsons, R. A. (2004). Mapping fuels and fire regimes using remote sensing, ecosystem simulation and gradient modeling. Ecological Applications, 14(1), 75-95. https://doi.org/10.1890/02-5145

Saaty, T. L. (1980). The analytic hierarchy process: Planning, priority setting, resource allocation. McGrawHill. https://www. worldcat.org/title/analytic-hierarchy-process-planning-priority-setting-resource-allocation/oclc/5352839\#div_lists_similar_items

Sakr, G. E., \& Elhajj, I. H. (2010). Artificial intelligence for forest fire prediction: A comparative study. Proceedings of the Sixth International Conference on Forest Fire Research (pp. 653661). Coimbra.

Satir, O., Berberoglu, S., \& Donmez, C. (2016). Mapping regional forest fire probability using artificial neural network model in a Mediterranean forest ecosystem. Geomatics, Natural Hazards and Risk, 7(5), 1645-1658.

https://doi.org/10.1080/19475705.2015.1084541

Sharma, L. K., Kanga, S., Nathawat, M. S., Sinha, S., \& Pandey, P. C. (2012). Fuzzy AHP for forest fire risk modelling. Disaster Prevention and Management, 21(2), 160-171. https://doi.org/10.1108/09653561211219964

Sitanggang, I. S., Yaakob, R., Mustapha, N., \& Ainuddin, A. N. (2013). Predictive models for hotspots occurrence using decision tree algorithm and logistic regression. Journal of Applied Sciences, 13(2), 252-261.

https://doi.org/10.3923/jas.2013.252.261

Sowmya, S. V., \& Somashekar, R. K. (2010). Application of remote sensing and geographical information system in mapping forest fire risk zone at Bhadra wildlife sanctuary, India. Journal of Environmental Biology, 31(6), 969-974. https://pubmed.ncbi.nlm.nih.gov/21506484/ 
Stolle, F., Chomitz, K. M., Lambin, E. F., \& Tomich, T. P. (2003). Human ecological intervention and the role of forest fires in human ecology. Forest Ecology and Management, 179(1-3), 277-292. https://doi.org/10.1016/S0378-1127(02)00547-9

Stolzenburg, W. (2001). Fire in the rainforest. Nature Conservancy, 31, 22-27.

Suresh, B. K. V., Roy, A., \& Prasad, P. R. (2016). Forest risk fire modelling in Uttarakhand Himalaya using TERRA satellite datasets. European Journal of Remote Sensing, 49(1), 381-395. https://doi.org/10.5721/EuJRS20164921

Teodoro, A. C., \& Duarte, L. (2013). Forest fire risk maps: a GIS open source application - a case study in Norwest of Portugal. International Journal of Geographical Information Science, 27(4), 699-720.

https://doi.org/10.1080/13658816.2012.721554

Thapa, S., \& Engelken, R., (2020). Optimization of pelleting parameters for producing composite pellets using agricultural and agro-processing wastes by Taguchi-Grey relational analysis. Carbon Resources Conversion, 3, 104-111. https://doi.org/10.1016/j.crcon.2020.05.001

Vadrevu, K. P., Eaturu, A., \& Badarinath, K. V. S. (2010). Fire risk evaluation using multicriteria analysis - a case study. Environmental Monitoring and Assessment, 166(1-4), 223-239. https://doi.org/10.1007/s10661-009-0997-3

Vahidnia, M. H., Alesheikh, A., Alimohammadi, A., \& Bassiri, A. (2008). Fuzzy analytical hierarchy process in GIS application. The International Archives of the Photogrammetry, Remote Sensing and Spatial Information Sciences, XXXVII(Part B2), 593-396. https://citeseerx.ist.psu.edu/viewdoc/download?do $\mathrm{i}=10.1 .1 .155 .2544 \& \mathrm{rep}=$ rep $1 \&$ type $=$ pdf

Vakalis, D., Sarimveis, H., Kiranoudis, C. T., Alexandridis, A., \& Bafas, G. V. (2004). A GIS based operational system for wildland fire crisis management. I. Mathematical modelling and simulation. Applied Mathematical Modelling, 28(4), 389-410. https://doi.org/10.1016/j.apm.2003.10.005

Vasconcelo, M. J., Silva, S., Tome, M., Alvim, M., \& Pereira, J. M. C. (2001). Spatial prediction of fire ignition prob- abilities: Comparing logistic regression and neural networks. Photogrammetric Engineering \& Remote Sensing, 67(1), 73-81. https://www.asprs.org/wp-content/uploads/pers/2001journal/ january/2001_jan_73-81.pdf

Vasilakos, C., Kalabokidis, K., Hatzopoulos, J., \& Matsinos, I. (2009). Identifying wildland fire ignition factors through sensitivity analysis of a neural network. Natural Hazards, 50(1), 125-143. https://doi.org/10.1007/s11069-008-9326-3

Yakubu, I., Mireku-Gyimah, D., \& Duker, A. A. (2015). Review of methods for modelling forest fire risk and hazard. African Journal of Environmental Science and Technology, 9(3), 155-165. https://doi.org/10.5897/AJEST2014.1820

Yakubu, I., Mireku-Gyimah, D., \& Asafo-Adjei, D. (2018a). Hybrid methods for optimisation of weights in spatial multicriteria evaluation decision for fire risk and hazard. World Academy of Science, Engineering and Technology, International Journal of Geotechnical and Geological Engineering, International Scholarly and Scientific Research \& Innovation, 12(12), 723-728. https://www.researchgate.net/publication/330193883_Hybrid-Methods-for-Optimisation-ofWeights-in-Spatial-Multi-Criteria-Evaluation-Decision-forFire-Risk-and-Hazard

Yakubu, I., Ziggah, Y. Y., \& Peprah, M. S. (2018b). Adjustment of DGPS Data using artificial intelligence and classical least square techniques. Journal of Geomatics, 12(1), 13-20. https://isgindia.org/wp-content/uploads/2018/05/Pap_2_ JoG_Vol_1_No2_April_2018.pdf

Zadeh, L. A. (1965). Fuzzy sets. Information and Control, 8(3), 338-356. https://doi.org/10.1016/S0019-9958(65)90241-X

Zumbrunnen, T., Pezzatti, G. B., Menéndez, P., Bugmann, H., Bürgi, M., \& Conedera, M. (2011). Weather and human impacts on forest fires: 100 years of fire history in two climatic regions of Switzerland. Forest Ecology and Management, 261(12), 2188-2199. https://doi.org/10.1016/j.foreco.2010.10.009 